$\square j \mid\left\{\begin{array}{l}\text { Revista internacional } \\ \text { de Historia } \\ \text { de la Comunicación }\end{array}\right.$

\title{
RAZA, ELITE Y LIDERAZGO. La imagen de Obama como propaganda de Estado ${ }^{1}$
}

\section{RACE, ELITE AND \\ LEADERSHIP. Obama's image as state propaganda}

DOI: http://dx.doi.org/10.12795/RiHC.2013.i01.11

Amparo Guerra Gómez - aguerrag@ccinf.ucm.es / amparoguerragomez@yahoo.es Pablo Sapag Muñoz de la Peña - pvsapag@pdi.ucm.es / psapag@yahoo.com Universidad Complutense de Madrid

Resumen: Barack Obama llega a la presidencia de los Estados Unidos en un momento especialmente difícil de las relaciones de ese país con el resto del mundo. Las guerras en Iraq y Afganistán deterioraron su imagen en plena decadencia económica del país. Las muy especiales características personales de Obama-condición de mulato y formación de elite, entre otras- le permitieron evitar que la raza y la cuestión social polarizaran en negativo una campaña en la que en realidad esas cuestiones solo aparecieron tangencialmente. Lo interesante es que nada más anunciarse su victoria, los EEUU aprovecharán la equívoca percepción exterior en relación a Obama y sus características para mejorar su imagen internacional a partir de esas cosas apenas tratadas en la campaña. Así, las máximas autoridades de EEUU proyectan la idea de

\footnotetext{
${ }^{1}$ Investigación Financiada por el Programa de Creación y Consolidación de Grupos de Investigación BSCH-UCM GR58/08. Grupo de Investigación: 940460 Estrategias Persuasivas. Propaganda Política y de Guerra, y por el Grupo de Investigación UCM 930580 Historia y Cultura de los Estados Unidos. Proyecto I+D+i MICINN (HAR2009-13284)
} 
que Obama es el primer presidente negro, afroamericano e hijo de inmigrante de la historia de los EEUU, obteniendo así el Estado evidentes réditos propagandísticos. Este artículo aborda la construcción de la imagen nacional e internacional de Obama a partir de sus discursos públicos y los trabajos académicos sobre esa cuestión así como el análisis del papel que el periodismo corporativo juega en esa estrategia.

Palabras clave: Obama; EEUU; imagen; propaganda; raza; relaciones internacionales.

\begin{abstract}
Barack Obama becomes US President at a time when his country had very poor relations with the rest of the world. Wars in Iraq and Afghanistan have diminished US influence in the world at the very moment in which its economy was steadly going down. Obama's very special characteristics -mixed race and elite education, among others- allowed him to avoid the influence that a negative racial and social debate could have had in the outcome of the election. Those matters were not real issues during the campaign. The interesting finding is that based on the ambiguous perception on Obama abroad those subjects were used by US authorities since the very moment in which his victory was announced. In that sense the US could project itself as a state in a positive propaganda way in order to improve its image abroad. Thus the US backed the overseas' idea that Obama is the first black afroamerican and the first son of an immigrant in US history to reach the presidency. This paper looks over the construction of Obama's internal image and its projection in the international arena aided by corporate journalism. To do so we work with Obama's public speechs and other academic works on that question.
\end{abstract}

Keywords: Obama; USA; propaganda; image; race; international relations. 


\section{Introducción}

La originalidad de Barack Obama como político y emblema exterior de los Estados Unidos reside en ser un producto que rompe con las características tradicionales del líder presidencial. Así es por su proyección transversal a partir de sus especiales características raciales y su origen multicultural y social. También por los aspectos populistas y de contenido emocional que un representante de la generación post Vietnam, de clase media y educación en centros superiores de elite desarrolla en una campaña caracterizada por la nueva ordenación sectorial del votante estadounidense. Todo ello se manifiesta en forma de una imagen, un carisma y un liderazgo eminentemente mediático en base al nacimiento, la experiencia y la publicación de una obra biográfica que afecta a unos colectivos muy concretos a los que en estricto rigor él no pertenece: la población negra afroamericana y las minorías latinas visiblemente vinculadas a la inmigración económica.

Ellos son la fuerza política y social del nuevo siglo americano, a los que, sin descuidar al resto del panorama electoral, se dirige la retórica de Barack Obama (Pérez de las Heras, 2008: 114, 203). Lo hace de manera dinámica y postracial, a la medida de una efectiva propaganda interior. Al presentarse a los estadounidenses como la gran esperanza de cambio y credibilidad tras la polémica era Bush, justo en el momento en el que la crisis financiera se hacía pública en el mundo occidental. El recién llegado a la carrera presidencial se ofertará entonces como la esperanza (hope) de un cambio (change) que, sin alejarse demasiado de la clase gobernante o financiera, sea percibido como ese soplo de aire fresco capaz de cambiar el rumbo político y social del país.

Igualmente, y en el plano internacional -fundamental al hablar de un país que, aunque menguante, sigue siendo la potencia hegemónica mundial- el futuro 44 Presidente se proyectaba como la representación de la potencia unipolar garante e integradora de un mundo multipolar y multicultural. Unos EEUU que buscan la colaboración con Europa, pacificar definitivamente Oriente Medio y África y establecer una alianza con los países emergentes (BRIC). En definitiva, personificación en Obama de todo un mensaje propagandístico al servicio del Estado que el nuevo mandatario proyecta a una sociedad internacional traumatizada por la guerra contra el terrorismo y sus proyecciones en Afganistán $y$, sobre todo, Iraq. Comunidad internacional desasosegada también por las cada vez más evidentes contradicciones iniciadas veinte años antes con la caída del muro de Berlín. Ese hito histórico fue el catalizador de un optimismo algo ingenuo, el mismo que tuvo en la teoría del fin de la historia de Fukuyama su resultado más visible y funcional a ese ideal de globalización desbocada y sin contrapesos.

Dos décadas después el crecimiento de la desigualdad económica en términos sociales y territoriales y unos procesos migratorios asociados a la globalización y percibidos más como una amenaza, habían mudado el estado de ánimo general. En lugar de la 
euforia, un malestar desconfiado y del que con o sin razón se responsabilizaba a las políticas de unos Estados Unidos que con distinto énfasis, según la administración de turno, se habían convertido en adalides de esa globalización apoyada en el libre mercado, la democracia liberal y la uniformidad cultural a partir del american way of life. En ese marco irrumpe un Barack Obama que por sus propias características personales ofrece al mundo, como antes lo hizo en el interior, una imagen distinta, en este caso al servicio de la recuperación de Estados Unidos como actor internacional.

\subsection{Hipótesis y líneas metodológicas}

El objeto de estudio de este trabajo es, pues, un personaje actual de primera magnitud sobre quién se ha escrito bastante en términos periodísticos. Sin embargo, sobre Obama aún queda mucho por hacer desde una aproximación académica y sectorial. Así es por la limitada perspectiva histórica y la imposibilidad de acceder a documentos relevantes sobre cuestiones públicas y de estado vinculadas a su gestión y, muy particularmente, a la construcción de su imagen pública. En este último sentido, su equipo partidario guarda aún con celo toda la documentación relativa a las claves, estrategias y tácticas de comunicación de un liderazgo aún en ejercicio. Eso mismo ocurre, con más restricciones todavía, desde la perspectiva de la utilización de Obama, en su condición de Presidente, como factor de promoción de la imagen exterior de los Estados Unidos, cuestión sobre la que este artículo igualmente intenta profundizar.

Teniendo en cuenta esas limitaciones, entendemos que el primero de los pilares funcionales de la construcción de la imagen interior de Obama y de su proyección propagandística exterior, aún en aparente contradicción con sus manifestaciones retóricas, sea la raza. Ese factor de distinción, sin embargo, se proyecta como instrumento de integración más que de enfrentamiento y/o exclusión. Aspecto primordial, no único pero imprescindible para articular los diferentes perfiles del candidato en su justa proporción humana, política, y mediática. Un liderazgo diferente que no hubiera sido posible construir ni mantener sin su pertenencia a una elite de educación superior, segundo ingrediente para el ejercicio de una profesión en un mundo de blancos, y para el acceso a la carrera política. Polifacético aspirante de su tiempo, se ganó a los intelectuales sin por ello ofender a las clases medias y minorías, que vieron en la "Obama Generation" de jóvenes educados en buenas universidades y no en los seminarios de la causa negra, a profesionales de éxito asentados y cómodos con el establishment (Denton Jr., 2008: 120-122). Barack Obama era la mejor prueba de su ascenso social y económico, pese a no ser en estricto rigor, ni negro racialmente, ni afroamericano étnicamente ni tampoco primera generación de una familia de inmigrantes económicos. 
En coherencia con los ámbitos clásicos de la estructuración propagandística, esta exposición se detiene en la diferenciación de etapas y fases de actuación persuasiva (Pizarroso, 1990: 26-28) más aún al tratarse de un líder estadounidense. Conquista, primero, y, más tarde, consolidación y proyección internacional del poder, o lo que es lo mismo, frente interno y externo, siendo el primero aquel que se corresponde con los inicios políticos y la fulgurante campaña que, en menos de dos años, llevó a un joven y casi desconocido senador por Illinois a la Presidencia de los Estados Unidos. Exitosa base, pues, para una propaganda de Estado que se manifiesta como tal una vez que Obama se instala en la Casa Blanca, y que refuerza su imagen en ambos frentes: nacional e internacional. Fenómeno que para el mundo circundante no se hace visible hasta la primavera de 2008 , cuando el candidato ya parece seguro ganador.

Respecto de las principales recursos utilizados para este ensayo, y en tanto estén disponibles las fuentes primarias ahora bajo reserva por mandato público o por interés partidario, debemos resaltar en el caso que nos ocupa el gran valor de lo biográfico, toda vez que esta disertación recurre principalmente a bases documentales: los propios discursos del candidato. Sin olvidar la imprescindible consulta de ensayos especializados sobre su perfil político y los que tratan sobre propaganda y medios de comunicación. Sin contribuciones como Dreams of My Father, The Audacity of Hope o la recopilación Change We Can Believe In -además de las biografías de Michelle Robinson Obama- no hubiera sido posible rastrear el espíritu de un periodo en el que Obama basculó desde la candidatura presidencial a la toma de posesión. A ellos se suman distintos textos sobre propaganda (Pizarroso) y medios de comunicación (Davis) así como sobre la proyección propagandística de los líderes prolíticos estadonidenses (Greenstein, Cornog).

En otros órdenes, y lejos de lo meramente descriptivo, esta aproximación sectorial a la figura pública del actual presidente de los EE.UU. tiene tras si años de investigación en el marco de proyectos de carácter interdisciplinar sobre imagen y liderazgo en recientes elecciones presidencias estadounidenses, contando en su haber con una monografía presidencial (Jimmy Carter), además de recientes capítulos de libro sobre la proyección internacional de Barack Obama. Un estudio que marca un camino que los autores pretenden seguir desde las bases propuestas aquí y que se considera necesario como contribución al conocimiento histórico y mediático de un tipo de liderazgo nacional e internacional a profundizar por Obama en su recién estrenado segundo mandato. 


\section{El frente interno: unión, identidad y ecos de los Civil Rigths}

A mediodía del 20 de enero de 2009 prestaba juramento el 44 Presidente de los Estados Unidos de América. Barack Obama culminaba así su triunfante carrera venciendo obstáculos, arrastrando a minorías, a jóvenes e intelectuales, y fraguando consensos entre las filas de su propio partido. Incluso entre republicanos progresistas y electores indecisos. Todo ello con una promesa de gobierno síntesis de anteriores presidencias: la conquista y convicción de Abraham Lincoln (Lincoln, 1957: 138-139) la confianza de Kennedy (Barnes, 2005: 57-78), la visión ética de Jimmy Carter y el eclecticismo de Bill Clinton (Guerra Gómez, 2008, 2010a). Todo eso junto a la utilización de una racialidad ambigua y atemperada o exagerada según las necesidades propagandísticas.

Fue así como el candidato pudo eludir el debate racial. Lo hizo con autoridad, la misma que emana de una condición que en verdad es peculiar y nada general, desviándolo hacia el discurso de la multiculturalidad. Porque en realidad Obama es mulato y no negro, y no tenía porque sentirse aludido ante quienes quisieron llevar la campaña al terreno racial. Pero no sólo eso. Tampoco entró en querellas derivadas de la etnicidad, que como es sabido ni mucho menos se compone exclusivamente del elemento físico. Obama no es afroamericano, que en sentido estricto supone descender de aquellos africanos que fueron llevados como esclavos a los Estados Unidos y permanecieron en esa condición durante siglos sin que su liberación formal supusiese mejorar en todos los órdenes y mucho menos ser considerados como iguales por la mayoritaria sociedad blanca estadounidense. Obama tampoco es hijo de inmigrantes de primera generación, como de manera equívoca se le catalogó, sin que su equipo de campaña lo desmintiera en su momento, más bien todo lo contrario. Su padre keniata no era un trabajador inmigrante como los millones que han poblado los Estados Unidos desde mediados del siglo XIX en adelante. Era un profesional que había obtenido una beca para perfeccionar sus estudios en una prestigiosa universidad de los Estados Unidos. Condición bien distinta de la del extranjero corriente. En el Servicio de Inmigración lo saben, por eso las tarjetas de residencia son de distinto color según el caso.

De haber sido blanco o descendiente de esclavos, es muy posible que la campaña hubiese marchado por otros derroteros, entre otros motivos porque sus discursos habrían sido necesariamente diferentes. Su misma esposa Michelle, negra, afroamericana y de origen social humilde -las dos categorías anteriores no necesariamente presuponen la tercera- se ocupó de recordar a todos cómo el peso de una biografía influye, y mucho, en lo que se dice y en lo que se permite decir en términos históricos y sociales en una campaña presidencial (Ligthfoot, 2008: 114 y ss, Leanne, 2009: 62 y ss). En definitiva, y sin falsear sus antecedentes, realmente únicos y muy minoritarios, Obama logró de este modo no molestar a nadie. $\mathrm{O}$, lo que es mejor 
en términos de comunicación social persuasiva y de masas (Pizarroso, Ibid.) agradar a todos o a casi todos.

Si algo es permanente en su imaginario es la invocación a Abraham Lincoln. Las reminiscencias del presidente abolicionista llegaban justo en el momento en que Norte y Sur celebraban el bicentenario de su nacimiento (1808). En cierta forma Obama se presenta como su alter ego de Illinois. Ideológicamente se alienta la idea de que es un demócrata negro predicando la concordia nacional entre razas y culturas. Porque, como abogado de reducido ejercicio profesional y limitada experiencia política, asistente social en las comunidades del South Chicago (Pérez de las Heras, 2008: 8182 ), compartía con Abe su deseo de cambiar las cosas desde arriba en esta 'House Divided' que continúan siendo los EE.UU. del nuevo siglo (Obama, 2009: 64, 68).

Sobre cuándo Obama empieza a sentirse afroamericano, por qué y a través de qué personas, familiares, o amigos, las teorías confluyen en un mismo punto de desarrollo personal y político, como él mismo manifiesta en su obra biográfica. Una memoria de búsqueda y reconocimiento inspirada por la noticia de la muerte de su progenitor, al que apenas conoció, y cuya trayectoria decide rastrear en el país de origen: Kenia, donde aquél terminó sus días por un accidente de tráfico. Noticia que su hijo estadounidense recibe en Nueva York como alumno de la Universidad de Columbia "your father was a terrible driver" ${ }^{2}$, recuerda haberle explicado su madre (Obama, 2004: 6).

El deficiente recuerdo y la idealización del distante -versión de los abuelos, actitud de su progenitora- son igualmente responsables de su educación y de su visión del mundo circundante. Impacto de la pérdida, y conversación de adulto en compañía de su madre y hermana, le deciden a intentar resolver el dilema que un joven de sus características no puede aplazar más: la asunción de una identidad. No necesariamente la real, aunque fundamental para poder proyectarse hacia los demás (Said, 2001) y, a la postre, ser percibido por ellos. Máxime cuando uno aspira a convertirse en figura pública.

\subsection{Construyendo identidad. Entre EEUU y Kenia}

A la pregunta de cómo es Obama racialmente hablando: si negro, blanco, africano, medio asiático o sólo "is/ander" ${ }^{3}$, multiculturalidad, experiencia y destino son las respuestas posibles. Un mestizo fruto de la corta relación entre un universitario de Kenia ampliando estudios en los EEUU y una madre blanca estadounidense con

\footnotetext{
2 "Tu padre era un pésimo conductor".

3 Isleño, por su periodo de residencia en Hawai.
} 
antepasados de distintas etnias transplantada a la parte oceánica de los Estados Unidos. La limitada convivencia con ella ayuda a grabar tanto como a reconstruir sus recuerdos de la edad adulta. Con su traslado a Indonesia, ya divorciada y llevando consigo a Barry en un segundo matrimonio del que le da una hermana, Stanley Ann Dunham, joven antropóloga, intenta hacer funcionar su idea de interracialidad. Proyecto de vida que queda interrumpido por su prematura muerte pero que forja en la mentalidad infantil de su hijo una particular visión de otras tierras y pueblos.

De vuelta al lugar de nacimiento, los abuelos maternos retoman a su cargo la educación del pequeño en un ambiente tolerante de ausencia paterna, mitad mito, mitad silencio- le verá por última vez a los diez años de edad. Todo ello favorecido por las muy peculiares características de un Hawai que, aún siendo territorio estadounidense, no concentra la misma problemática y tensión étnica y racial de otros estados de la Unión. Lugar ideal por tanto para un Barack Obama que en otros emplazamientos, y en términos identitarios, hubiese tenido que enfrentarse a mayores presiones raciales, culturales y sociales.

Años después, dentro y fuera de los Estados Unidos, comienza la búsqueda de una identidad propia a través de la colaboración con su supuesta comunidad de color, para conocer y poder sentirse, al menos funcionalmente, lo que no es: un afroamericano de generación; adopción necesaria para la proyección de una imagen pública equilibrada y favorable políticamente. No obstante el proceso habrá de superar coyunturas personales y profesionales, como establecer la propia verdad sobre sus orígenes y sobre los condicionantes existentes para un estadounidense mestizo de clase media y bien educado que ha residido y viajado a otros países, aunque todavía no aún a Kenia.

La decisión de rastrear allí la historia de un padre al que sólo ha visto dos veces en su vida, forma parte de una tradición arraigada en la literatura y la experiencia vital afroamericana. Este recorrido sentimental y de raíces por el país de sus ancestros, descendientes directos de la orgullosa tribu de los Luo $^{4}$-, sirve al joven graduado para escribir Dreams from My Father (1995, 2004), primera obra autobiográfica que recoge sus experiencias por varios continentes. Aunque la norteamericana sea la más larga y duradera. En esta narración presidida por la decisión que todo individuo de color, o que se dice de color, debe finalmente tomar sobre quién o qué será en su vida adulta, testimonios propios y ajenos ayudan a Obama a revestirse con el blackness ${ }^{5}$ necesario para difuminar su realidad racialmente mulata y culturalmente mestiza -tragedia para algunos, exótico atractivo para otros (Swan, 2009: 91 y ss)- a los ojos de otros lectores y futuros votantes. Ejercicio de identidad con el que, al mismo tiempo, gana experiencia vital e intelectual con vistas a posteriores actividades.

\footnotetext{
${ }^{4}$ Etnia procedente de Sudán establecida junto al lago Victoria hace siglos, donde constituye el segundo grupo más numeroso tras los kikuyu.

${ }^{5}$ Negritud.
} 
Obama consagrará, por tanto, un mes a la búsqueda de sus raíces africanas y de una identidad racial y de destino. En ese periodo, y tras conocer y visitar a su abuela así como a primos y otros parientes de segunda y tercera línea, Obama descubre quién puede ser. En este particular Auma, su hermanastra profesora universitaria en Nairobi, le ha venido haciendo partícipe del fraccionamiento emocional que comparten los hombres y mujeres de su raza con formación alta: culpabilidad, división de sentimientos ante lo que se presenta como una vida mejor de superación de lo ancestral, aunque quizás traidora a sus orígenes. Fraguar un destino diferente, o abandonarlo todo en pos de la llamada de la tierra. Tentación esta última que puede ser tan destructiva como inútil. La solución se la da a ambos Rukia Odero, antigua profesora de Historia de ella y amiga de su padre (Obama, 2004: 432-435). Ante la pregunta de si existe lo genuinamente africano y si hay algún modo de adaptarse a las contradicciones culturales y emocionales que padecen sus paisanos, no valen las respuestas académicas o políticas: es algo tan simple, personal, y difícil como elegir ("All you can do is choose" ${ }^{\prime 6}$ ). Y hacerlo tantas veces como surja el dilema: país donde establecerse, tipo de vida, costumbres, educación o leyes. Es el precio de vivir en un mundo híbrido, en el que siempre es más efectivo buscar lo conciliable y válido antes que lo puro o ideal (Ibidem).

\subsection{La retórica de la no-raza como propaganda de un "liderazgo colectivo"}

There's the United States of America. There's not a black America and a white America and Latino America and Asian America: there's the United States of America ${ }^{7}$

Estas palabras del recién llegado senador junior en la Convención Demócrata de julio de 2004, que en un principio debía pronunciar Bill Clinton, corresponden a una de las intervenciones más arropadas de la historia electoral de los Estados Unidos. En ella Obama habla de la tolerancia de un país que no pone barreras a un nacido entre dos continentes para alcanzar altas cotas de formación y estatus. Así lo entendieron sus progenitores al ponerle un nombre africano: Barack (Blessed) - "the diversity of my heritage, aware that my parents dreams live on my precious daugthers. I stand here

6 "Lo único que puedes hacer es elegir".

7 The Audacity of Hope. Tomado de Barack Obama. Words that Inspired a Nation. Essential speeches: 2002 to the Inauguration (foreword by Victor Dorff): New York, Falk River Press, 2009, p. 23. La cita puede traducirse como: "Existen los Estados Unidos de América. No existen unos EEUU negros, blancos, latinos o asiáticos. Existen los Estados Unidos de América". 
knowing that my part is part of the larger American story" (Obama, 2009: 18-20) ${ }^{8}$. Con The Audacity of Hope, título que toma del sermón dominical de un reverendo poco antes de la muerte de Harold Washington -primer alcalde negro de Chicago-, la raza se vuelve biopic electoral. Aludiéndola en sus componentes, pero sin nombrarla, pasa a instalarse en la línea discursiva de quién cuatro años después será designado por su partido candidato a la Presidencia de los Estados Unidos. Continuación de una búsqueda espiritual e intelectual y de una temprana decisión en la que el color de la piel no debía ser nunca una barrera. En todo caso, como apuntaron medios de comunicación y especialistas (Cohen, 2008; Richards, 2008), la candidatura de Barack Obama se constituyó en demostración de cuanto seguía afectando la raza al juicio público ${ }^{9}$, algo que para ellos operaría favorablemente para el candidato.

Otra cuestión fueron los tonos de piel, suficientes o no según qué parte de la opinión pública o de los intelectuales la formulara. Una vez anunciadas sus intenciones políticas, la polémica mediática sobre si Obama era "suficientemente negro", "menos negro que el resto", "medio blanco", afroamericano o sólo "africano" -de lo racial a lo étnico- dominará la escena republicana, conservadora y de minorías en el año previo a la elección. Falso debate, escribió Gregory Rodríguez ${ }^{10}$, de lo evidente y visible, primando sobre las demostradas habilidades discursivas, políticas o de escritor, por causa de la acepción que asocia lo afroamericano como concepto étnico ligado a ancestros que han compartido una experiencia histórica en un continente diferente: la de la esclavitud. Algo que, sin embargo, no tenía este hijo de padre keniata ni por origen ni por formación cultural.

Al mismo tiempo surge la necesidad de conculcar la percepción de Obama como peligro para el voto negro más que como luchador por la igualdad de oportunidades. Para la columnista de Chicago Sun Times y profesora de De Paul University Laura Washington, es el primer obstáculo a derribar en las percepciones iniciales. No será el nuevo Jesse Jackson -demasiado joven para haber vivido la lucha por los Civil Rights aclaraba Donna Brazile (Wilson, 2008: 70 y ss), aunque sí alguien que, cuarenta años después, recogía el legado con el que Luther King marcó a las siguientes generaciones. Su imagen accesible de post-racialidad resultó una hábil manera de construir una historia alternativa, única, que abrazaba la identidad negra sin renunciar por ello a la parte anglo del Medioeste, su otra herencia. En ese contexto Michelle Obama resulta fundamental. Campeando con destreza el temporal de "pureza", poco pesaron esos

\footnotetext{
8 "La diversidad de mi herencia, la conciencia de que los sueños de mis padres viven en mis preciosas hijas. Yo me preento aquí sabiendo que la mía es parte de la muy extensa historia de los Estados Unidos".

${ }^{9} \mathrm{Cfr}$. al respecto "Implicit Race Bias and the 2008 Presidential Election: Much Ado About Nothing?" http://www.pennumbra.com/debates/debate.php?did=20 [Consulta 22/09/2011]

10 Is Obama the new 'black"? http://www.latimes.com/news/printedition/opinion/la-oprodriguez17dec17,0,7336980.column. [Consulta 05/01/2011]
} 
seis primeros meses en quién, tanto en primarias como en la fase presidencial, recibirá el 90\% del voto negro (Denton Jr., 2009: 102, 103 y ss). Y lo hará, entre otras cosas, por la percepción, ajustada o no, de su raza.

El anuncio a la candidatura a la Presidencia en la misma escalinata del capitolio de Springfield en la que Lincoln lo hiciera doscientos años antes (This Improbable Quest ${ }^{11}$ ) es otro hito para quien debe enfrentarse a unas laboriosas primarias con los pesos pesados del partido, con la cuestión racial reapareciendo a cada paso y el apoyo del votante negro dividido entre Hillary Clinton y Obama casi a partes iguales (Richards, 2009). Tanto así que, tras arrasar en lowa la polémica mediática surge por unas declaraciones de Michelle Obama, que las voces republicanas se apresuraron a señalar como propias del resentimiento afroamericano, forzando a una segunda declaración en la que la aspirante a Primera Dama matizaba lo que realmente la hacía sentirse orgullosa de los EEUU mas allá de su marido, que fie lo que dijo en primera instancia: For the first time in my adult lifetime, I'm really proud of my country, and not just because Barack has done well, but because I think people are hungry for change ${ }^{12}$.

Las lágrimas en directo de Hillary -no tan simbólicas como las que se le escaparán a Obama al conocer la muerte de su abuela Madelyn Payne Durham-, provocaron el vuelco de New Hampshire para su contrincante. Será la "no victoria" más famosa y efectiva de su tiempo, fruto de la esperanza en una lucha que para nada debe ser improbable, y un himno identificativo para un discurso que no deja a nadie indiferente, por ser el origen de un slogan global: Yes, We $\operatorname{Can}^{13}$. Como sucediera en los 60, el nuevo movimiento había encontrado su letanía. Tras 16 meses de batalla electoral, la senadora Clinton abandonaba. No sólo renunciaba a su objetivo de convertirse en la primera Presidenta, sino que exhortaba a sus partidarios a respaldar la candidatura del senador por Illinois -la manera de continuar es retomar nuestra energía, nuestra pasión, nuestra fuerza, haciendo todo lo posible para ayudar a Barack Obama.

\subsection{El tempo (Pizarroso, Ibid.) de la propaganda electoral. Conmemorando a Lincoln y a King}

Martin Luther King es el segundo referente histórico en Estados Unidos para este candidato, prueba viviente de un melting pot que nunca estaría completo sin la

\footnotetext{
${ }^{11}$ Esta búsqueda improbable.

12 http://blogs.abcnews.com/politicalpunch/2008/02/michelle-obam-1.html. Consulta 1/4/2011. Traducción: "Por primera vez en mi edad adulta, realmente me siento orgullosa de mi país y no solo porque Barack lo ha hecho bien, sino porque pienso que la gente está hambrienta de cambio".

${ }^{13}$ Sí podemos.
} 
incorporación real de la comunidad afroamericana. Con Obama convertido en probable mandatario y espejo de una integración que comenzó hace décadas, el aniversario de la muerte del líder de los Derechos Civiles (Remembering Dr. Martin Luther King Jr., Indiana, 4 de abril) es la ocasión para reunir en un mismo eco (I have a Dream $^{14}$ ) las esperanzas de Rosa Parks -simbólico funeral de Estado que el todavía senador refiere en sus memorias (Obama, 2006: 269 y ss)-, y las de todos aquellos que le siguieron en su lucha por las libertades y la igualdad. En un discurso en el que ya se apunta como candidato presidencial por el partido Demócrata habla de historia y de raza para unir su proyecto al del reverendo de Memphis, y a su lucha no en términos antisegregacionistas, sino de justicia universal: It was a struggle for economic justice ..., for freedom, for dignity, and for humanity ${ }^{15}$. Según Obama, además, la misma lucha del político que le siguió en la muerte pocos meses después: Robert F. Kennedy.

Un sueño que halla su relevo en este siglo, y que los votantes pueden ver hoy realizado en otras generaciones, en las que cada uno debe cumplir su parte en la consecución del techo que King persiguió durante toda su vida. Pero si existió un momento idóneo para la propaganda biográfico-étnica, fue el de la respuesta institucional de Obama, ya avanzada la carrera, a las declaraciones del reverendo Jeremiah Wright (God damm America for its racism and for killing innocent people ${ }^{16}$ ), el pastor que le inició al cristianismo, y su guía durante años. Sus palabras, difundidas por las principales cadenas de televisión y multiplicadas en Youtube, provocaron la ira nacional, provocando que su autor fuese apartado del African American Religious Leadership Committee. Como apuntó The New Yorker, A More Perfect Union, discurso compuesto al dictado por Jon Favreau es clave para su nominación como candidato a la presidencia, como contundente declaración pública de quién reconoció haberse distanciado hacía meses de Wrigth. Pronunciado el 18 de marzo de 2008 en el National Constitutional Center de Filadelfia, constituye una efectiva respuesta propagandística en tiempo y forma a los sucesos acaecidos durante uno de los servicios en la United Trinity Church de Chicago.

Rechazando la expresividad equívoca de Wright (not only wrong but divisive ${ }^{17}$ ), Barack Obama se presenta como representante y defensor de la interracialidad desde las mismas bases de la historia afroamericana. El preámbulo de la Constitución de los Estados Unidos -We the People, in order to...-, y las líneas lincolnianas, se prestan a la promesa de una nueva era de avance y superación de las heridas nacionales, como líder iconográfico de las nuevas generaciones y del cambio en las mentalidades. Por orígenes, por vínculos y por integración: I am the son of a black man from Kenia and a

\footnotetext{
14 Tengo un sueño.

15 “Fue una lucha por la justicia económica..., por la libertad, por la dignidad y por la humanidad".

16 "Malditos sean los EEUU por su racismo y por asesinar inocentes".

17 "No solo equivocadas, también divisorias - de la sociedad-"
} 
white woman from Kansas. I was raised with the help of a white grandfather who survived a Depression to serve in Patton's Army during World War II, and a white grandmother who worked on a bomber assembly line at Forth Leavenworth while he was overseas... I am married to a black American who carries with her the blood of slaves and slaveowners- an inheritance we pass on to our two precious daughters. I have brothers, sisters, nieces, nephews, uncles and cousins of every race and every hue, scattered across three continents, and for as long as I live, I will never forget that in no other country on earth is my story even possible ${ }^{18}$ (Obama, 2009: 93).

Sin disculpar a su ex mentor, pero explicando las posibles causas de su comportamiento, Obama habla de un pasado que sigue ahí y que generaciones enteras tuvieron que sufrir, conteniendo su ira mientras la discriminación vivía en los Estados Unidos como política de Estado, con el racismo como su más eficaz instrumento (Wilson, 2008: 91-92). No sólo para aquellos que lo padecían directamente por causa del color de su piel. También para el otro lado, en forma de odios, de desconfianzas, o de dolorosas contradicciones en personas partidarias de un cambio. Incluso su propia abuela, esa segunda madre que le crió en la tolerancia, llegó a sentir miedo al cruzarse por la calle con hombres negros y a manifestarse a veces mediante estereotipos que hicieron sentir extraño al pequeño Barry (Obama, 2009, 93 y ss). La encrucijada estaba ahí: o continuar con esta realidad lamentable de decenios, o resolver conjuntamente los problemas de convivencia que viene teniendo los EEUU. Es la decisión a la que se enfrentan gobierno y ciudadanos. Las perdurables consecuencias de un huracán Katrina que golpéo especialmente a los afroamericanos, la educación, la sanidad, la deslocalización de los empleos o el cuidado de los mayores son también temas de un discurso que los medios de comunicación destacaron, subrayando el énfasis en esa reconciliación y comprensión necesaria para perfeccionar, en el siglo XXI, la inacabada unión de 1787.

¿Existe acaso algo más atractivamente racial que un candidato a la presidencia pretendidamente negro pidiendo la superación de prejuicios ancestrales que aún existen y funcionan en el autoproclamado país de las oportunidades? Un aspirante completamente blanco no podría haberlo planteado con igual éxito. Ni tampoco referirse a casos presentes como él lo hizo presentando a Ashley Baia, la niña y hoy joven mujer (23 años) de Florence, South Carolina, que hizo frente a la pobreza que le suponía atender a su madre enferma de cáncer y que, con los mayores sacrificios,

\footnotetext{
18 "Soy hijo de un hombre negro de Kenia y de una mujer blanca de Kansas. Crecí con la ayuda de un abuelo blanco que sobrevivió a la Depresión y que sirvió en el ejército de Patton durante la Segunda Guerra Mundial y de una abuela blanca que trabajó en una cadena de montaje de bombarderos en Fort Leavenworth mientras él estaba en ultramar. Estoy casado con una estadounidense negra que tiene sangre de esclavos y de esclavistas - una herencia que hemos legado a nuestras dos preciosas hijas. Tengo hermanos, hermanas, sobrinas y sobrinos, tíos y primos de todas las razas y matices dispersos por tres continentes y mientras viva jamás olvidaré que en ningún otro país mi historia sería posible".
} 
superó los infortunios (Ibid.: 104-105), para ayudar a sus semejantes y estar ahora en la campaña de Barack Obama... I am here today because of you, Ashley ${ }^{19}$.

Uniendo a blancos y negros en torno a la polémica provocada por Wright, Obama ganaba igualmente sobre el dilema de los red/blue states, con su discurso cohesivo, mas allá de la mera invocación a Lincoln o a Kennedy. $O$ de los ataques mediáticos de las celebrities de McCain (Paris Hilton, Britney Spears). La negritud es utilizada aquí como "máscara", afirma Shelby Steele (Denton Jr. et alt., 2008: 108, 118 y ss), que facilita la decisión a la población blanca y reduce la necesidad de la inocencia racial a la redención de un pasado vigente, mientras su imagen de una país postracial sirve a la decencia de sus posiciones. Ya no caben excusas para la inactividad afroamericana cuando tenemos (tengamos) a uno de los nuestros en la Casa Blanca. Eficacia de un mensaje que venía a demostrar algo aún más evidente: que, en términos programáticos, las diferencias entre Obama y Clinton no fueron tales. Después, la positiva cobertura mediática del "Hope and Change", tándem redundante que, además de suavizar cualquier percepción de racialidad explícita, se mostró realmente poderoso, no sólo en la captación de otras minorías sino de conservadores y swing voters.

Un logro en el que no todos estuvieron de acuerdo. Desechando la nostalgia de los Jacksons, Sharptons o del mismo reverendo Wright, esta retórica de lo políticamente aceptable que modifica la acostumbrada gratitud del negro por la moralidad de sus acciones constituía para el profesor afroamericano Derrick Bell (NYU) un peligroso giro a la derecha, por lo que representa de fin a la acción afirmativa de decenios de los luchadores de los Civil Rights (Ibid.: 120 y ss).

\subsection{Del interior al exterior. Obama como propaganda de Estado}

A primeros de noviembre de 2008, aquellos temas que aparecían lejanos o tangenciales durante la campaña -raza y etnicidad-, o en los que se trabajaba con sigilo con vistas a la captación de nuevas minorías, aparecieron como un torrente en la noche electoral. Todos, partidarios o detractores del hasta entonces candidato demócrata, se apresuraron a decir sin ambages que era el primer presidente negro en la historia de los Estados Unidos y el primer afroamericano en llegar a la Casa Blanca. Y es que la propaganda funciona con metáforas y, sobre todo, con la percepción de los receptores. Incluyendo a los de fuera de su país. Al referirse a su padre como inmigrante -gancho interior para los latinos-, daba aún mayor proyección a lo que ya

\footnotetext{
19 “Estoy aquí gracias a tí, Ashley”.
} 
aquella memorable noche de noviembre comenzó a ofrecer en forma de réditos propagandísticos a la proyección exterior de un Estado: Obama como reflejo de un país donde todo es posible. Obama como la encarnación del país global y multicultural por antonomasia. Obama a la altura de un Lincoln que abolió la esclavitud y de cuyo nacimiento -la propaganda se hace también tirando de calendario, el tempo de la propaganda (Pizarroso)- se cumplía el segundo centenario. Eficaz y global utilización del triunfo electoral de Obama por parte de los máximos portavoces norteamericanos, que entendieron perfectamente el estado de ánimo de las audiencias exteriores, en un momento en que la percepción sobre los Estados Unidos alcanzaba sus cotas más negativamente bajas a partir de la guerra de Iraq, con la imagen de un George W. Bush considerado unilateralista, confrontacional y simple. En todo ello había que sumar lo que se consideraba excesivo fanatismo confesional del 43 Presidente, característica incomprensible en una Europa cada vez más alejada del hecho religioso (AA. VV., 2009b). Aprovechamiento que asimismo alcanzaba a la incapacidad de las audiencias exteriores para percibir matices de raza, etnia y condición social en un contexto estadounidense y que, a lo largo de la campaña, tan hábilmente manejó el actual Presidente. Para esas audiencias transatlánticas, no existió debate posible: Obama era negro, afroamericano e hijo de inmigrante.

Idea no explicitada abiertamente durante la campaña pero que aparece con fuerza una vez que ha ganado los comicios. Lo hace por boca de demócratas y republicanos, caso del mismo George Bush, que aludió a los jóvenes afroamericanos cuando en la noche electoral valoró la victoria de Obama de la siguiente forma: La elección de este presidente es el reconocimiento al trabajo duro, el optimismo y la fe en la promesa de nuestra nación. Al utilizar el artículo estaba singularizando a Barack Obama, destacando su condición única, a la que asocia esos elementos tan caros a la idealización de los Estados Unidos: el valor de la meritocracia y la creencia en un futuro siempre mejor para esa "nuestra nación". En definitiva, la de todos, más allá de la raza, la etnia o la condición social, en palabras de su antecesor en la presidencia, como había demostrado la campaña de 2008.

Esa concepción de los mejores valores estadounidenses encarnados en Obama, se alimentará a su vez desde fuera. Hasta los enemigos más declarados de EEUU y de sus aspectos más negativos -precisamente los que Obama permite atenuar- reforzaron el mensaje. Así lo hizo un presidente venezolano Hugo Chávez que no había escatimado críticas a Bush y a la idea de unos EEUU antipáticos por imperialistas, se rendía a la Obamanía al señalar: (...) la elección histórica de un afrodescendiente a la cabeza de la nación más poderosa del mundo es el síntoma de que el cambio de época que se ha gestado desde el Sur de América podría estar tocando a las puertas de los Estados Unidos. 
Otro de los dirigentes que aceptaba acríticamente la proyección de Obama como encarnación de un "sueño americano" sin barreras raciales, étnicas o sociales fue el brasileño Luis Ignacio Lula Da Silva, triunfante presidente de un Brasil que desde mediados del siglo XX definió su política exterior a partir de su rechazo a una hegemonía de los Estados Unidos sin rivales en el hemisferio occidental -contrapeso que obviamente se reservaba para sí mismo, más aún después de la pérdida de liderazgo latinoamericano de México y sudamericano de Argentina. No sorprendió pues su asunción de la idea que los Estados Unidos proyectaban de Obama, quizás por pensar que como él -Lula es de extracción obrera- había superado los estigmas sociales. Tal vez porque en Brasil, con un 52\% de afrobrasileños, también descendientes de esclavos, era oportuno dar un mensaje anclado en la cuestión racial que el propio Lula -blanco de origen portugués- nunca podría ofrecer. De ahí su rotunda afirmación: Quien dudaba de que un negro pudiera ser presidente de Estados Unidos ahora sabe que puede, y sólo puede porque eso sucede en un régimen democrático que permite que la sociedad se manifieste.

Si mandatarios nada sospechosos de condescendencia con los Estados Unidos, ni personalmente ni como representantes de sus estados, se rindieron de tal manera a una simplificación identitaria de Obama en beneficio de la imagen exterior de los Estados Unidos, tampoco resulta extraño que en un tiempo de simplificaciones informativas, resultado de la imposición a escala planetaria del "corporate journalism" y del "flat Earth news" (Davis, 2009) tan útil a la propaganda, la prensa mundial recibiera con una nada asombrosa unanimidad su victoria. "El candidato demócrata se convierte por mayoría abrumadora en el primer presidente negro de la historia de Estados Unidos". El titular del diario español El País, se ve apoyado por una crónica de Antonio Caño en el que los matices aparentes que introduce sólo sirven para reforzar la idea principal: "El viaje se acaba, declaró Obama nada más depositar su voto en Chicago. Fue algo más: el sueño americano se hizo realidad en la figura de un senador de 47 años, nacido en Hawai, hijo de padre africano y de nombre Barack Hussein Obama". Lo mismo ocurre cuando otros periodistas que por su condición de anglosajones sí pueden conocer más los matices de la raza y la clase-especialmente si son británicos- abordan el triunfo de Obama. Textos y matices, frente a la simplificación general, esa que subraya la equívoca idea de que Obama es la demostración de que el "sueño americano" es posible. Reproducimos a continuación el análisis de John Carlin en el mismo diario, en el que aclara con datos y realidades las diferentes categorías que aquí trabajamos, la de la raza, el grupo étnico y la clase social. Carlin no solo disecciona con claridad los matices que las sitúa como categorías distintas, también explica cómo y porqué se perciben de manera diferente en los propios Estados Unidos y fuera de ellos, donde en realidad se confunden. En tal sentido, la cita que reproducimos conecta con una de las claves de la propaganda, a saber, la necesidad de construir mensajes atendiendo no sólo a lo que se quiere decir o 
proyectar, sino a la forma en la que esos mensajes pueden ser percibidos por distintos receptores (Pizarroso, Ibid):

(...) Mucho se ha comentado sobre el hecho histórico de que Barack Obama sea negro. Y lo es, lo cual es muy positivo para Estados Unidos, y quizá incluso para el mundo. Pero tampoco es negro del todo, lo cual también es positivo. / Como nos recordó la foto que todo el mundo vio ayer del joven Obama con sus abuelos maternos, es mestizo. Sólo que, por los misterios de la biología, lo que predomina en su rostro son los genes de su padre keniano. / Que se le perciba como negro es bueno para la América negra. Manda un mensaje de un valor incalculable. El victimismo ancestral de los afroamericanos, los descendientes de los esclavos, ha inhibido la evolución de este sector de la población en lo económico, lo político y lo social. El hecho de que el color de la piel apenas influye en la capacidad de prosperar de los habitantes del "país de las oportunidades" se ha demostrado en el notable éxito que han tenido los recientes inmigrantes africanos, cuyos ingresos y nivel educativo han estado por encima de los de la media del país (...) Esto no significa que los blancos o los hispanos o los de origen asiático tengan que sentirse de ningún modo amenazados o excluidos de la fiesta. Porque ellos también pueden reconocerse en Obama, o pueden ver en él un americano medio más. Por su porte, por su aire y, ante todo, por su forma de hablar inglés, Obama no corresponde al estereotipo del negro americano con el que se asociaba a un fallido candidato negro anterior, Jesse Jackson. Cuando uno habla por teléfono con un estadounidense desconocido detecta inmediatamente, en 90 casos de cada 100, si la persona es negra. El afroamericano tiene un acento distintivo, con una clara nota sureña que lo delata, independientemente del lugar de Estados Unidos en el que viva o haya nacido. / Obama no habla así. Obama habla como un blanco típico de clase media de Connecticut o Colorado. En cuanto a las palabras que usa y cómo las ordena, está en otra órbita comparado con George W. Bush, por poner un ejemplo. Habla con la elocuencia, claridad y amplitud de vocabulario del más eminente abogado o profesor universitario. Pero no deja de tener visibles raíces africanas, lo que implica que todo el mundo no sólo pueda identificarse con algún aspecto de él, sino que ofrece el ejemplo de una persona digna y susceptible de emular. Obama combina los atributos del continente en el que se originó la especie humana con los del infinitamente variado país en el que él nació. Es un hombre para la eternidad (El País 5/11/2008).

La descripción que hace Carlin permite entender porqué Obama ha sido un buen producto propagandístico, tanto a nivel interno como externo. En el primer caso porque se han explotado con acierto las muy peculiares características de Obama para que todos pudieran sentirse identificados con él y para que nadie se sintiese amenazado. Así ha sido porque Obama es todo y nada al mismo tiempo: negro, afroamericano, descendiente de inmigrante, blanco, anglosajón, exitoso abogado de 
clase media alta, etc. Desde la perspectiva exterior, el mundo ha visto en Obama lo que quería ver: unos Estados Unidos donde todo es posible, desde lo peor, representado por el mandato de Bush que tantas tensiones internacionales generó, hasta lo mejor: la posibilidad de que un negro, afroamericano e hijo de inmigrante le sucediera en la presidencia de los Estados Unidos.

\section{Colores de una carrera de fondo. El elitismo de un líder mediático}

La raza fue a la imagen de Obama lo que género y edad fueron para Hillary Clinton y John McCain durante la elección, demostrando claramente, frente a las prevenciones de sus apoyos -incluido el discutido "efecto Bradley" ${ }^{20}$, su impacto en las encuestas. Aunque, como dejab claro Carlin, no es menos cierto que una educación en la excelencia formaba parte de las claves visuales y simbólicas del crecimiento público del candidato de Illinois desde la etapa de su segunda juventud. Años en la Costa Este y la Ivy League para la formación superior de un Obama procedente del Occidental College. Una elección meditada que garantiza el acceso al mercado laboral e institucional de un profesional que en pocos años se dará a conocer como aspirante al Senado de los Estados Unidos.

Recién llegado a Chicago, tras pasar por Columbia University (1985-1987) donde se gradúa en Ciencias Políticas, el South Side es su oportunidad de asentar una identidad social afroamericana, gracias a la oferta que le hacen un grupo de iglesias (Obama, 2008: 193 y ss) para trabajar como asistente (community organizer) con las clases menos favorecidas de la ciudad del Michigan. Como uno más entre ellos, a pesar de la formación que pronto completará en Harvard (licenciatura en Derecho entre 1992 y 1994), estación siguiente en el trayecto hacia un nuevo liderazgo. En breve, la recuperación de la foto del hijo del doctor Obama en atuendo casual apoyado en la columnata de entrada de la Harvard Law School, como "primer presidente negro" de su prestigiosa revista, pone la dosis de elite para la construcción mediática de una imagen lista para proyectarse a sus futuros votantes y gobernados ${ }^{21}$. Como promesa

\footnotetext{
${ }^{20}$ Término acuñado tras la derrota sufrida en 1982 por Tom Bradley, aspirante afroamericano a gobernador de California, pese a que las encuestas a pié de urna pronosticaron una victoria holgada a su favor. Análisis post-electorales no siempre compartidos adujeron factores sociales (temor a ser tachado de racista) a la hora de explicar tan bajo porcentaje de un voto blanco que declaró públicamente su apoyo. Otro tanto sucedió con los votantes "indecisos", que lo hicieron finalmente por George Deukmejian, candidato republicano y de raza blanca.

${ }^{21}$ No deja de sorprender hasta el momento, la escasísima información que sobre el acceso de Barack Obama a la dirección de tan prestigiosa publicación de elite proporcionan los numerosos artículos y biografías, tanto pre como post presidenciales.
} 
del cambio primero. Pronto, como su artífice e icono universal de su tiempo, apto para ganar el apoyo del votante blanco joven, universitario y con alto nivel de ingresos (Richards, 2009).

De vuelta en Chicago Obama recala como abogado en el bufete donde conocerá a Michelle Robinson, oriunda del South Side y destacada profesional -"black and brilliant $^{22 " ~(L i g h t f o o t, ~ 2009: ~} 14$ y ss, 30-32, Mundy, 2008: 182 y ss)-, que trabajó para la administración de Richard Daley tras estudiar en Princeton y Harvard. Con Barack como su estrecho asesor, su amistad pronto convertida en relación sentimental tras vencer las iniciales prevenciones de ella (Mundy, 2008: 151 y ss, Obama, 2006: 388389), es un valor para que Obama obtenga el reconocimiento de un colectivo al que aún deberá convencer. Ella será su mitad afroamericana y su gran apoyo: "su roca" (my rock), como gusta afirmar en público; síntesis familiar, cultural y afectiva que, como señaló en su momento la desaparecida Geraldine Ferraro, ayudará a Obama a convertirse en una versión positiva de la raza. Suficientemente atractivo y moderado para liderar a colectivos heterogéneos. Algo que no hubiera logrado (Denton Jr. ed., 2009: 104 y ss) de ser cien por ciento blanco. Superando el habitual discurso del "victimismo negro", el aspirante alejaba los ataques conservadores, para intentar conectar con las otras minorías (asiáticos, latinos) en los meses que seguirán a su victoria en las primarias demócratas (Richards, 2009).

En 2002, como joven senador por Illinois, casado, con dos hijas, y habiendo cambiado su residencia de Grant Park por el más selecto distrito de Hyde Park, es momento para que el matrimonio Obama amplíe contactos con las elites de Chicago, reorganizando sus respectivas actividades profesionales y familiares (Obama, 2006: 398 y ss) en pos de una segunda y más prometedora etapa de la carrera política de él. Aquella que, en breve, le conducirá al centro neurálgico del poder: Washington D.C. y su escaño por la representación federal. Una vez en Capitol Hill, las relaciones y actuaciones en diversos Comités del "primer senador de color" son las de un liberal moderado y contemporizador a la búsqueda del consenso bipartidista que consiga la aprobación conjunta de leyes de ámbito social y medioambiental.

Ya sea como el "Kennedy negro" o, simplemente, como un WASP funcional, Obama rompe con la línea antiintelectualista presidencial que inaugurara Ronald Reagan (Lim, 2008: 115, 119 y ss). Tan simplificadora y discursivamente descuidada, tan alejada de la concepción aristocrática de los 'Founding Fathers', y del concepto de "presidencia pedagógica" de Delano Roosevelt: You are more than a president, more than a leader, you are an educator ${ }^{23}$-resalta el profesor Michael Genovese (2008: 101-105) en su particular "espejo" para futuros mandatarios. Una máxima oscurecida por los efectos

\footnotetext{
22 "Negra y brillante"

23 "Eres más que un presidente, más que un líder, eres un educador".
} 
colaterales de un personalismo populista en el que participaron Clinton y, por supuesto, George W. Bush-, propio de una era de "política espectáculo" y ataque al enemigo, donde la forma (packaging) prima sobre el fondo (substance) y vacía de significados al discurso convirtiendo a la ciudadanía en espectador cínico, ignorante, y no comprometido (Lim, 2008:120-122). Trivialización retórica que el nuevo "Communicator in Chief" (Hendricks y Denton Jr., 2010) transformará comunicativamente con su inteligente síntesis entre persuasión basada en la cercanía y disertación de nivel.

En esa labor, la doble utilización del soporte visual y digital para difundir en tiempo record la temática de su mensaje político-social resultó inestimable. Autores como Jerome R. Corsi (2008) hablaron de "culto a la personalidad" de un candidato secundado por seguidores y simpatizantes que ignoraban puntos no tan claros del background de Obama, como sus conexiones con Kenia y el Islam, su pertenencia a la teología de la liberación afroamericana, o sus relaciones con el constructor Tony Rezko. Si no peligroso proselitismo, al menos resultado de un contagioso star system en lo referente a su carrera política. Así lo manifestó en su momento Joe Klein (Time Magazine), al afirmar que la campaña de Obama, más que sobre temas o causas, excluyendo un amorfo manifiesto del cambio, versaba sobre su persona, sobre su capacidad de inspirar. Y sobre lo maravillosa que estaba resultando en sí misma ${ }^{24}$.

\subsection{Soportes del éxito: el ubicuo atractivo persuasivo de un e-President}

En estudio colectivo sobre aspectos mediáticos y no mediáticos de la primera elección de Obama, Lynda Lee Kaid (Denton Jr., 2008: 209-210, 226) se refiere a la "orgia de dinero" que caracterizara la financiación de la propaganda electoral presidencial 2004. Los cada vez mayores gastos electorales y el concurso de Internet habían alterado la financiación desde los ya lejanos tiempos de los controles de la FCC (1975-2001), convirtiendo en agente activo al donante de pequeñas cantidades gracias a las redes sociales y a los 'infomercials', acentuando con ello el estilo popular de unas primarias que marcaron estilo tras los excesos de la segunda campaña de George W. Bush (Ibid.: 185-187). A su manera, Barack Obama tomará nota de ello. Su fundraising vía Twitter en los primeros meses le permitió rechazar la financiación oficial y de PACs en favor de un sistema más seguro (por masivo) para un aspirante de sus características. Para Trudy Lieberman (Columbia Journalism Review), sin embargo, y con datos del Center for Responsive Politics sobre las cantidades recibidas por cada candidato en

\footnotetext{
${ }^{24}$ http://blogs.abcnews.com/politicalpunch/2008/02/and-obama-wept.html. Consulta 29/3/2011
} 
primarias $^{25}$, se trata de una verdad a medias. Sin olvidar que, en el último tramo de campaña, el soft money comenzó a fluir desde empresas, instituciones y lobbies varios que no querían quedarse fuera del "cambio" que prometía Obama.

En lo relacionado con el uso de soportes mediáticos tradicionales, videos y spots (ads), algo más tardíos en el caso de Obama, compartieron contenidos ético-emocionales con el estilo de producción de Clinton -incluso con la de McCain-, afirma Kaid (Denton Jr. ed., 2008: 214-215). El tono diferencial Ilegará con las presidenciales y sus respectivos temas de campaña: economía y plan sanitario del demócrata, frente a guerra al terrorismo del republicano. En una campaña en la que la innovación viene de la mano de las nuevas tecnologías, ubicuas y de inmediato efecto amplificador, las estrategias de ataque, en respuesta al personalismo aducido por McCain (Ambition), resultaron más frecuentes en Obama (It's Get Worse, Embrace). En la era de la decadencia del poder de convocatoria de los partidos políticos, el 'Obamaphenomena' luce imagen de masas en el Taco Bell Arena de Idaho (14.000 personas), con el candidato revelación como candidato consagrado. En esos espacios masivos pero también en los town meetings. Así describe Jeffrey P. Jones (Denton Jr. et alt., 2008: 170-190) el populismo visual de una campaña en la que, más que los productos televisivos, lideró I've Got a Crush on Obama, video debido al website BarelyPolitical reproducido en YouTube, y más comúnmente conocido por "Obama Girl", con sus réplicas republicanas (McCain Mama, Giuliani Girl). Tipo de metraje igualmente utilizado en primarias por Hillary y John Edwards con un montaje diferente (Hendricks and Denton Jr. eds., 2010: 93 y ss).

No menos importantes resultaron las nominaciones en revistas como Rolling Stone o Ebony (25 Coolest Brothers of All the Time), o las compareciencias del candidato de la mano de los reyes del talk show: Ophrah Winphrey, Tyra Banks, Jay Leno, y Martha Stewart. O para 60 minutes de Larry King, uno de los más vistos, además de su criticado pero efectivo paso por Saturday Night Live. En la gran pantalla, habitual división de apoyos en un Hollywood donde el 'Obama Team' incluía a Angelina Jolie, Jennifer Aniston, Sandra Bullock, Heidi Klum y otros fieles abanderados de la nueva causa (Denton Jr. ed., 2008: 181). Kate Walsh, Rihana, o la misma Scarlett Johannson no dudaron en prestar imagen y voz al grupo formado por el rapero Will I Am para el video Yes, We Can, parafraseo artístico, musical y visual del himno de campaña, construido con imágenes de estudio, eslogans y metraje del recordado discurso.

Consciente de la fuerza del directo para ganar credibilidad, los Obama tampoco dejaron de lado la eficacia del documental de campaña. Siguiendo la senda de Clinton y con David Axelrod en el equipo, el ejemplo de The War Room (1993) brinda ocasión a Amy Rice y Alice Sims para realizar con HBO By the People. The Election of Barack Obama (2008), un relato interiorista ('behind the scenes') de la campaña desde lowa:

${ }^{25} \mathrm{Cfr}$. http://www.cjr.org/campaign desk/obamas lobbyist line.php Consulta 19/12/2010 
el caucus paso a paso, hasta la misma noche de la elección. Metraje pleno de emotiva espontaneidad gracias a la participación de la familia y de todos y cada uno de los que hicieron posible la victoria. A través de sus imágenes, de las declaraciones y entrevistas al candidato, a Michelle y a las hijas de ambos, Sasha y Malia, historia, raza y familia se revelan como elementos fundamentales en el sostenimiento de tan larga carrera. El producto: un documento histórico accesible, de interés político y gran carga persuasiva. Naturalidad y uso de la Pop Politics, afirma Bruce E. Gronbeck (Ibid.: 228243) matizando otro de los grandes estereotipos mediáticos de la campaña de 2008: el omnímodo poder de Internet en la movilización de votantes por quien se presentaba como el futuro e-president. Por encima de la labor de America for Obama en captación de bases, información o canvassing, fueron las redes sociales su más efectiva herramienta de propaganda entre nativos digitales y minorías. Así, Politics 2,0 Smackdown (Will Tech save Democracy?) conectaron colectivos de una nación hasta entonces dispersa. Junto a blogs y páginas ad hoc (Moveon.org, NewAssigment. Net), la labor de YouTube y Twitter, además de conducir donaciones, lideraban una ubicuidad electoral que, más que al compromiso de voto, contribuyó a consolidar el producto Obama como auténtica "marca política" (Hendricks and Denton Jr. eds., 2010: 37-48).

\section{La consolidación internacional de un líder del siglo XXI}

Que los presidentes de los Estados Unidos representan a los mismos tanto dentro como fuera de su territorio es algo asociado a sus funciones en el cargo. No lo es tanto que la singularidad de uno de ellos lo termine convirtiendo en algo más allá de esa representación básica planetariamente aceptada. Tan sólo con Kennedy ocurrió algo similar, dejando aparte a los Padres Fundadores, o a Abraham Lincoln, modelo por excelencia para un Obama que descubrió en el elocuente líder de la Emancipación ese "algo más" que ofertar a una sociedad digital. Y que mejor que haberse convertido, además de en 44 presidente, en un auténtico instrumento al servicio estratégico de la propaganda de Estado en un momento especialmente delicado para la imagen de su país, tanto interior como exteriormente. Consecuencia de la Guerra en Iraq. También de la falta de resultados en Afganistán, de la vulnerabilidad e inseguridad asociadas a los atentados terroristas el 11-S y del declive económico que hizo que el PIB de los EEUU rozara apenas el 19\% del mundial, cuando medio siglo antes suponía casi la mitad. El mérito fue por supuesto del candidato, pero también de sus asesores de campaña, que supieron posicionarle como un individuo tan singular y único como los millones de individuos globalizados de un supuesto e ideal mundo sin fronteras con 
identidades compartidas e intercambiables. Obama, en definitiva, sería como ellos: post-racial, posnacional, y estaría más allá de cualquier consideración sociológica.

Con todo, y a nivel de promesa electoral, Barack Obama tardaría en despertar el interés a nivel de expertos y analistas internacionales -incluyendo estadounidenses y anglos, además de las habituales reticencias de académicos europeos y latinos. Solo tras lowa la visibilidad del candidato comienza a ser real, si bien no tan manifiesta como la que arrancará tras la nominación demócrata oficial, a finales de agosto de 2008.

\subsection{Presidente Obama: la fuerza exterior de una imagen}

Tampoco resulta sorprendente que, una vez convertido en primer mandatario y símbolo -la propaganda de Estado necesita igualmente de ellos- de los Estados Unidos de América, su imagen y carisma estuvieran destinados a pervivir. Con independencia del balance de su gestión política. Previamente se había procurado un lugar destacado como nuevo interlocutor de la escena internacional. Una labor cuidadosamente preparada desde los primeros viajes exteriores como favorito a la Casa Blanca, apostando fuerte, señala Nancy Snow (Henricks and Denton Jr. eds., 2010: 79), mostrándose como Presidente sin serlo aún.

Esta estrategia puede observarse en su visita a la capital alemana, en julio de 2008, y en el discurso $A$ World that Stands as One, con el candidato a las mismas puertas de la nominación demócrata. Frente a la columna coronada por la dorada "Elsie", Obama aparece ante la multitud congregada en el Tiergarten berlinés como un John Kennedy redivivo. El presidente que denostó la construcción del Muro, y el casi presidente que celebra su desaparición en un nuevo siglo. Una misma llamada que se reproduce en la historia. Como ya lo hiciera la figura de la New Frontier en aquellos días aciagos People of the world, look at Berlin! es el exhorto del nuevo líder unipolar a estadounidenses y alemanes tras el cambio (change) y la esperanza (hope) que trajo para muchos supuso aquel noviembre de 1989. Animándoles a derribar otros tantos muros y a superar desafíos pendientes: el de las etnias, el racismo, la pobreza, la religión; a parar el crecimiento armamentístico, y salvar al planeta de la polución. Objetivos aparentemente inalcanzables ante los que los dos países puedan volver a reinventar el mundo (Obama, 2008: 261-271). La Cumbre de Praga, en abril de 2009, mantiene aún ese calor electoral de un Presidente que hablaba al mundo de la urgencia de una reducción nuclear con referencia a los tratados START pendientes de renovación. 
Otros lazos y acercamientos entre naciones y continentes deben ser igualmente posibles. La subsiguiente visita de Estado a Egipto es momento para confirmar al mundo la nueva imagen exterior que los Estados Unidos buscan a partir del fenómeno Obama. Con A New Begining (El Cairo, 4 de junio de 2009), el Presidente llamó a la unión y comprensión entre razas y credos. El hijo cristiano de un padre keniata con numerosos parientes musulmanes, que ha vivido el rechazo y las acusaciones de conversión al Islam y que ha demostrado con palabras y hechos su potencial de tolerancia religiosa e igualdad racial. Aunque la gente no cambiara de la noche a la mañana, otra mirada era posible fue el mensaje de a quien, al menos por entonces, muchos escuchaban.

\section{Conclusiones}

Este trabajo demuestra que el equipo de comunicación de Barack Obama ha manejado con acierto la espinosa cuestión racial, étnica y social de todo político en un país tan heterogéneo en esas materias como los Estados Unidos. Así ha ocurrido en las tres fases en las que se centra este artículo. La primera de ellas es aquella en la Obama aspiraba a obtener la nominación del Partido Demócrata a la presidencia de los Estados Unidos. Entonces centró su campaña más que nada en su juventud, en su proyección como candidato fresco e inédito y por lo mismo poseedor de las condiciones necesarias para renovar la política estadounidense. De esa forma evitó con éxito que la campaña para las primarias se centrara en condiciones personales excluyentes, en su caso su supuesta condición de negro, afroamericano e hijo de inmigrante. Haberlo hecho habría permito a la senadora Hillary Clinton explotar al máximo la cuestión género, la idea de que podía ser la primera mujer en alcanzar la presidencia de los EEUU. Como Obama no se proyectó persuasivamente y de manera explícita como el primer negro, afroamericano, o hijo de inmigrante que podía aspirar con garantías de éxito a alcanzar la presidencia, Clinton tampoco pudo promover su campaña solo desde el hecho diferencial de su condición de mujer. Establecido con éxito el marco de la misma, la campaña debía girar en torno a la idea de la renovación de la política y de las propuestas concretas que ofrecía cada uno de ellos.

El no haber planteado una campaña de primarias con tintes dramáticos y excluyentes permitió a Obama recuperar fácilmente a Hillary Clinton para la segunda parte de su ascenso al poder: la campaña frente al republicano John Mcain. Durante la misma Obama y su equipo de propaganda tampoco cayeron en la tentación de explotar la cuestión racial. Obama se presentó a los electores más bien como un candidato posracial y ajeno a las etiquetas étnicas tan comunes en los EEUU. Superadas esas dos espinosas cuestiones, Obama tampoco tuvo problemas para prescindir de la cuestión 
social, la misma que aunque menos relevante que en Europa, en EEUU también puede jugar un papel entre ciertos colectivos de votantes. La omisión a esas tres variables no fue el resultado de la ambigüedad calculada, más bien del trabajo previo que el propio Obama había realizado para resolver su relación personal con sus poliédricos y contradictorias circunstancias raciales, étnicas y sociales. Por lo mismo Obama resultaba creíble al hablar de la armonía racial, étnica y social. Lo hacía, además, con la ductilidad que había aplicado al resolver el debate identitario personal. Obama siguió al pie de la letra el consejo de la profesora Rukia Odero en el sentido de que ante casos como el suyo lo adecuado era permitirse elegir cuántas veces fuese necesario la identidad con la cual sentirse cómodo. Si él lograba sentirse satisfecho consigo mismo, proyectaría una sensación igualmente positiva en los demás. Interiorizada la fórmula, Obama la propuso en la campaña a los propios estadounidenses a través del muy persuasivo Yes we can. Se aminoraba así de manera efectiva los sentimientos encontrados que algunos electores podían tener respecto a la elección de alguien como Obama y el debate más amplio sobre lo pertinente o no de un cambio a un liderazgo aparentemente tan contrapuesto al de Bush y otros presidentes. Todo ello utilizando de manera masiva las nuevas tecnologías de la información al servicio de la comunicación política.

El tercer frente es el exterior, sobre todo una vez que se consuma la victoria electoral del candidato. Entonces esos temas que se habían sorteado en las dos fases anteriores aparecen con fuerza. Obama, el candidato imposible de clasificar racial, étnica y socialmente dentro de los propios EEUU es proyectado al mundo exterior como el primer presidente negro, afroamericano e hijo de inmigrante de primera generación que alcanzaba la primera magistratura. Se convertía así el presidente en mensaje de propaganda al servicio de unos EEUU muy necesitados de mejorar su imagen internacional tras los episodios de Iraq y Afganistán. Demostró así el aparato de propaganda estatal una gran capacidad de utilizar en beneficio propio uno de los elementos esenciales a la hora de trazar una campaña propagandística: la percepción de los receptores. Como se ha demostrado en este trabajo, los matices raciales y étnicos que permitieron a Obama no ser percibido dentro de los EEUU como un político totalmente negro o afroamericano en beneficio de sus propósitos electorales, eran absolutamente desconocidos en el ámbito exterior. Por eso Obama pudo ser proyectado sin grandes esfuerzos al resto del mundo como lo que en realidad no era ni él había proyectado explícitamente durante su campaña. Esta cuestión nos permite reforzar uno de los principios de la propaganda: la necesidad de construir mensajes persuasivos de acuerdo a los receptores y en tal sentido diferenciar claramente entre propaganda interna y propaganda externa.

Lo interesante es que el propio aparato de propaganda de Obama, distinto al del Estado, no ha hecho nada por desmentir esa percepción que internacionalmente se 
tiene de él. Eso le ha permitido jugar con ventaja en la escena internacional, donde cabe recordar que recibió el Premio Nobel de la Paz antes de cumplir un año de mandato. Igualmente le ha permitido que acciones cuestionables, como la operación en Libia para derrocar a Gadafi, la intervención estadounidense en los asuntos sirios o la ejecución extra judicial del terrorista Osama Bin Laden sean percibidas con simpatía o indulgencia por otros actores internacionales y por una opinión pública mundial dispuesta a evaluar con no demasiada exigencia a quien pese a no serlo se percibe como el primer presidente negro, afroamericano e hijo de inmigrante de los Estados Unidos.

\section{Bibliografia}

AA.VV (2009a): Barack Obama. Words that Inspired a Nation. Essential Speeches: 2002 to the Inauguration (Forewod by Victor Dorff), New York: Fall River Press.

AA.VV (2009b): The blind spot. When journalists don't get religion. (Eds., P. Marshall; L. Gilbert y R. Green Ahmanson). New York: Oxford University Press.

BARNES, JOHN A.(2005): John F. Kennedy on Leadership. The Lessons and Legacy of a President, New York, AMACOM.

COHEN, MICHAEL H., "Does Race really Matter?" http://campaignstops.blogs.nytimes.com/2008/10/05/does-race-eallymatter/?pagemode=print Consulta 22/09/2011.

CORSI, JEROME R. (2008): Obama Nation: Leftist Politics and The Cult of Personality. New York: Threshold Editions/Simon and Schuster.

DENTON, ROBERT E. (editor) (2009): 2008 Presidential Campaign: a communication perspective. Lanhan Md.: Rowman \& Littlefield Publishers.

DAVIS, N. (2009): Flat Earth News. London: Vintage.

GENOVESE, M. A. (2008): Memo to a new president: the art and science of presidential leadership. New York: Oxford University Press.

GREENSTEIN, FRED. I. (2001), The Presidenctial Difference. Leadership Style from FDR to Clinton. With A New Afterword on George W. Bush. New Jersey, Princeton University Press. 
GUERRA GÓMEZ, A. (2008): La nueva imagen demócrata con Jimmy Carter. Liderazgo presidencial y estrategias de comunicación electoral para el siglo XXI. Málaga: Sepha Ediciones.

- (2010a), "Presidencia visual y democracia de la emoción. El liderazgo mediático en Primary Colors", en VV AA, Política y comunicación en la historia contemporánea (Coords. E. Bordería Ortíz; F. Martínez Gallego; I Rius Sanchos). Madrid: Fragua.

- (2010b), "Vientos de cambio. La imagen de Barack Obama en revistas españolas de política exterior", en VV AA, Historia y Comunicación en la España Contemporánea. Libro Homenaje a la profesora Ma Dolores Saíz (Coords., I. Martín Sánchez; A. Martínez de las Heras) Madrid: Facultad de Ciencias de la Información: Universidad Complutense.

- (2010c), “Estados Unidos y España ante la "Revolución Obama” Imágenes de un nuevo liderazgo", en VV AA, Norteamérica y España. Percepciones y relaciones históricas: una aproximación interdisciplinar (Eds.E.Sánchez Montañés, M. Sánchez Suárez. Málaga: Sepha.

HENDRICKS, J.A. Y DENTON R. E. (Editors), (2010): Communicator in -Chief. How Barack Obama Used New media Technology to Win The White House. Lanham, Maryland: Lexington Books.

"Implicit Race Bias and the 2008 Presidential Election: Much Ado About Nothing?" http://www.pennumbra.com/debates/debate.php?did=20 [Consulta 22/09/2011].

"Inside Obama's Weeping Victory", Pew Research Center Publications, November 5, 2008 http://pewresearch.org/pubs/1023/exit [Consulta 22/09/2011. ]

KRAUSE, D. G. (1995): El arte de la guerra para ejecutivos. El texto clásico de Sun Tzu adaptado a la vida de hoy. Madrid: Edaf.

LEANNE, S. (2009): Hablar como Obama. Barcelona: Profit Editorial.

LEVY, MICHAEL, "Barack Obama's Victory: The Myth That Race Didn't Matter", http://www.britannica.com/blogs/2008/11/barack.obamas

[Consulta 22/09/2011].

LIGTHFOOT, E. (2009): Michelle Obama. First Lady of Hope. Guilford, Connecticut: The Lyons Press.

LIM, E. T. (2008): The Anti-Intellectual Presidency. The Decline of Presidential Rhetoric from George Washington to George W. Bush. New York, Oxford University Press. 
LINCOLN, ABRAHAM (1957): Selected Speeches, Messages and Letters (edited and with an Introduction by Harry Williams), New York, Holt Rinehart and Winston.

MARTÍN BARBERO, J. (2005): "Identidad y diversidad en la era de la globalización", en VV AA, NEGRÓN, B., (ed) Diversidad cultural. El valor de la diferencia (Ed., B. Negrón). Santiago: LOM, 2005, p.149.

MUNDY, L. (2008): Michelle. A Biography, New York: Simon \& Schuster.

OBAMA, B. (2004): Dreams from My Father. A Story of Race and Inheritance, New York: Three Rivers Press.

- (2006): The Audacity of Hope. Thoughts on Reclaiming The American Dream. New York: Vintage Books.

- (2008): Change We Can Believe In. Barack Obama's Plan to Renew America's Promise. New York: Three Rivers Press.

OBOLER, S. (1997): Etnic labels, Latino lives: identity and politics of (re) presentation in the Unitade Status, University of Minnesota Press.

PÉREZ DE LAS HERAS, M. (2009): El Secreto de Obama. Madrid: LID.

PIZARROSO, QUINTERO, A. (1990): Historia de la Propaganda. Madrid: EUDEMA.

RICHARDS, ANDREW, "The 2008 Presidential Election in Historical Perspective, Tribuna Norteamericana (Julio 2009), Alcalá de Henares: Instituto Universitario de Investigación de Estudios Norteamericanos Benjamin Franklin, http://www.institutofranklin.net

SAID, E. (2001): Fuera de lugar. Barcelona: Grijalbo Mondadori.

SAPAG, P. (2006): "El terrorismo global y los conflictos identitarios", en VV AA, Nuevos temas de comunicación (Eds., J. Benavides Delgado; D. Alameda García y E. Fernández Blanco). Madrid: Fundación General Universidad ComplutenseAyuntamiento de Madrid, pp. 31-41.

SPITAELS, G. (2010): Barack Obama. El espejismo. Madrid: Editorial Popular.

SWAN, R. L. (2009): El método Obama. Barcelona: De Bolsillo.

WILSON, J. K. (2008): Barak Obama. This Improbable Quest. Boulder, CO.: Paradigm Publishers. 